Article

\title{
Impact Study of FY-3B MWRI Data Assimilation in WRFDA
}

\author{
Chun Yang *, Lijian Zhu and Jinzhong Min
}

Key Laboratory of Meteorological Disaster of Ministry of Education (KLME)/Joint International Research Laboratory of Climate and Environment Change (ILCEC)/Collaborative Innovation Center on Forecast and Evaluation of Meteorological Disaster (CIC-FEMD), Nanjing University of Information Science \& Technology, Nanjing 210044, China; zhulj@nuist.edu.cn (L.Z.); minjz@nuist.edu.cn (J.M.)

* Correspondence: yangchun@nuist.edu.cn

check for

updates

Citation: Yang, C.; Zhu, L.; Min, J. Impact Study of FY-3B MWRI Data Assimilation in WRFDA. Atmosphere 2021, 12, 497. https://doi.org/ $10.3390 /$ atmos 12040497

Academic Editor: Chanh Kieu

Received: 18 March 2021

Accepted: 12 April 2021

Published: 15 April 2021

Publisher's Note: MDPI stays neutral with regard to jurisdictional claims in published maps and institutional affiliations.

Copyright: (c) 2021 by the authors. Licensee MDPI, Basel, Switzerland. This article is an open access article distributed under the terms and conditions of the Creative Commons Attribution (CC BY) license (https:// creativecommons.org/licenses/by/ $4.0 /)$.
Abstract: In the first attempt to configure the Fengyun-3B satellite's Microwave Radiation Imager (MWRI) radiance data in the Weather Research Forecast (WRF) model's Data Assimilation system (WRFDA), the impact of MWRI data assimilation on the analysis and forecast of Typhoon Son-Tinh in 2012 was evaluated with WRFDA's three-dimensional variational (3DVAR) data-assimilation scheme. Compared to a benchmark experiment with no MWRI data, assimilating MWRI radiances improved the analyses of typhoon central sea level pressure (CSLP), warm core structure, and wind speed. Moreover, verified with European Center for Medium-Range Weather Forecasts (ECMWF) analysis data, significant improvements in model variable forecast, such as geopotential height and specific humidity, were produced. Substantial error reductions in track, CSLP, and maximum-wind-speed forecasts with MWRI assimilation was also obtained from analysis time to $48 \mathrm{~h}$ forecast.

Keywords: data assimilation; Microwave Radiation Imager (MWRI); typhoon; Weather Research Forecast model's Data Assimilation system (WRFDA)

\section{Introduction}

Since the 1960s, more than 200 meteorological satellites over the world have been launched into space. Satellite observing has been an indispensable part of the global observing system and the most extensive data resource in numerical weather prediction (NWP). Furthermore, with the development of satellite detection technology, the spatial and temporal resolutions of satellite observation have obtained much improvement. The instruments, which are carried on satellites, are sensitive to atmospheric temperature and humidity. Therefore, the assimilation of satellite data from microwave or infrared sensors can bring about significant improvement in weather forecasting [1-8].

The Fengyun (FY) series satellites were developed for broad meteorological and environmental applications in China [9]. So far, two generations of geostationary and polar-orbiting satellites have been developed. FY-3B is the second experimental satellite of the second generation of Chinese polar-orbiting satellites. There are 12 sensors onboard FY-3B for monitoring the Earth's atmospheric motion and severe weather events, including the Microwave Radiation Imager (MWRI), Medium-Resolution Spectral Imager (MERSI), Microwave Temperature Sounder (MWTS), and Microwave Humidity Sounder (MWHS). The radiance data from the MWRI, MWHS, and MWTS has been directly used in many operational centers, and led to a progressive estimate of the atmospheric state and improved weather-forecast accuracy $[10,11]$.

The first microwave imager is the Special Sensor Microwave Imager (SSMI) carried on the Defense Meteorological Satellite Program (DMSP)'s F-8 satellite. It was replaced by the Special Sensor Microwave Imager Sounder (SSMIS) on DMSP's F-16/17 [12,13]. Following the SSMIS, the Advanced Microwave Scanning Radiometer for Earth Observing System (AMSR-E) [14] was launched into space on the Aqua satellite. As the AMSR-E's successor, the Advanced Microwave Scanning Radiometer 2 (AMSR2) onboard the Global Change Observation Mission-Water 1 (GCOM-W1) [15] was widely used in operation 
models. Like these microwave imagers, MWRI can provide observational data related to various phases of water. It has 10 channels at five frequencies of $10.65,18.7,23.8,36.5$, and 89.0 GHz, with horizontal and vertical polarizations. Compared with the FY-3A-MWRI instrument, the FY-3B-MWRI has a higher stability and much lower nonlinearity [9]. The MWRI is a passive microwave sensor, which is essential to the retrieval of various surface parameters. The radiance data from the MWRI has been applied for soil moisture [16,17], snow cover [18], snow depth [19], and rain-rate retrievals [20]. However, the data quality and benefits of FY-3B-MWRI radiance in regional data assimilation have not been widely evaluated.

In this article, we discuss the first attempt to configure FY-3B-MWRI radiance data in the Weather Research Forecast (WRF) model's Data Assimilation system (WRFDA). The impact of assimilating MWRI radiance data will be evaluated for Typhoon Son-Tinh's analyses and forecasts. This paper is structured as follows: the WRFDA system used to assimilate satellite radiances and the MWRI radiance data are described in Section 2; Section 3 gives the experimental settings; the results of experiments are detailed in Section 4; and the final section provides a summary and some discussions.

\section{Model and Data}

\subsection{WRFDA System}

The WRFDA V3.8.1 system, one of the most popular data-assimilation systems for atmospheric research, was developed by the National Center for Atmospheric Research (NCAR). It suited for use in different scale applications, from regional and mesoscale modeling to global-scale modeling with multiple assimilation methods, such as threedimensional variational (3DVAR), 4DVAR, ensemble transform Kalman filter (ETKF), and hybrid (3DEnVAR, 4DEnVAR) [21]. All these data assimilation components can be used in both meteorological research and operational models. In this study, the 3DVAR scheme was chosen to assimilate clear-sky MWRI radiance data. It obtains an optimal estimation of the state of atmosphere by iterating the objective cost function (Equation (1)):

$$
J(\mathbf{x})=\frac{1}{2}\left(\mathbf{x}-\mathbf{x}_{b}\right)^{\mathrm{T}} \mathbf{B}^{-1}\left(\mathbf{x}-\mathbf{x}_{b}\right)+\frac{1}{2}(y-H(\mathbf{x}))^{\mathrm{T}} \mathbf{R}^{-1}(y-H(\mathbf{x}))
$$

where $\mathbf{x}$ represents the atmospheric state composed with model variables; $\mathbf{x}_{b}$ is the prior estimate of $\mathbf{x}$, called the "background"; $H$ is the nonlinear observation operator that maps $\mathbf{x}$ to observation space; and $\mathbf{B}$ and $\mathbf{R}$ are the covariance matrices of background error and observation error.

A variety of observations including radar data, precipitation data, wind speed/direction data, and satellite radiance data can be assimilated in WRFDA. For satellite-data assimilation, the operators are radiative transfer models (RTMs). Two of the most popular fast RTMs are Radiative Transfer for Television Infrared Observation Satellite Operational Vertical Sounder (RTTOV) and the Community Radiative Transfer Model (CRTM) [22], developed and maintained by the European Organization for the Exploitation of Meteorological Satellites (EUMETSAT) and the U.S. Joint Center for Satellite Data Assimilation (JCSDA) [23], respectively. These two RTMs have been interfaced with WRFDA, which can assimilate radiance data from several satellite sensors, even in an all-sky condition, with the two fast RTMs [5]. In this study, the CRTM 2.1.3 was used as the radiance observation operator to simulate MWRI radiance data, and model simulations were in a clear-sky condition.

\subsection{MWRI Data}

The MWRI is a conical scanner onboard the FY-3B polar-orbiting satellite. Similar to the AMSR-E onboard NASA's Aqua spacecraft and the AMSR2 onboard the Japan Aerospace Exploration Agency (JAXA)'s GCOM-W1, the MWRI was designed to provide information associated with precipitation, cloud water, and solid moisture, and to monitor tropical cyclones. MWRI has 10 channels at 10.65, 18.7, 23.8, 36.5, and $89.0 \mathrm{GHz}$ with different polarizations (vertical and horizontal) (Table 1). The low-frequency channels 
(channels 1 to 4 ) are more sensitive to surface emissivity and ocean rain, while channels 5 to 10 are sensitive to water vapor and clouds.

Table 1. Characterizations of the Fengyun-3B (FY-3B) satellite's Microwave Radiation Imager (MWRI) channels.

\begin{tabular}{ccccc}
\hline Channel & Frequency $\mathbf{( G H z )}$ & Polarization & Sensitivity $(\mathbf{K})$ & Resolution $\mathbf{( k m} \times \mathbf{k m})$ \\
\hline 1,2 & 10.65 & V, H & 0.5 & $51 \times 85$ \\
3,4 & 18.7 & V, H & 0.5 & $51 \times 85$ \\
5,6 & 23.8 & V, H & 0.8 & $27 \times 45$ \\
7,8 & 36.5 & V, H & 1.0 & $18 \times 30$ \\
9,10 & 89 & V, H & 1.3 & $18 \times 30$ \\
\hline
\end{tabular}

The MWRI scans the earth at a fixed angle of $45^{\circ}$, and each scan line contains 254 samples. It covers a width of $1400 \mathrm{~km}$ and completes one scan line in $1.7 \mathrm{~s}$. More details of the MWRI are shown in Table 1 . The Level 1 data, which was saved in ascending and descending versions for in this study, was provided by the National Satellite Meteorological Center (NSMC). The imager can cover about $80 \%$ of the total area in one day (Figure 1).

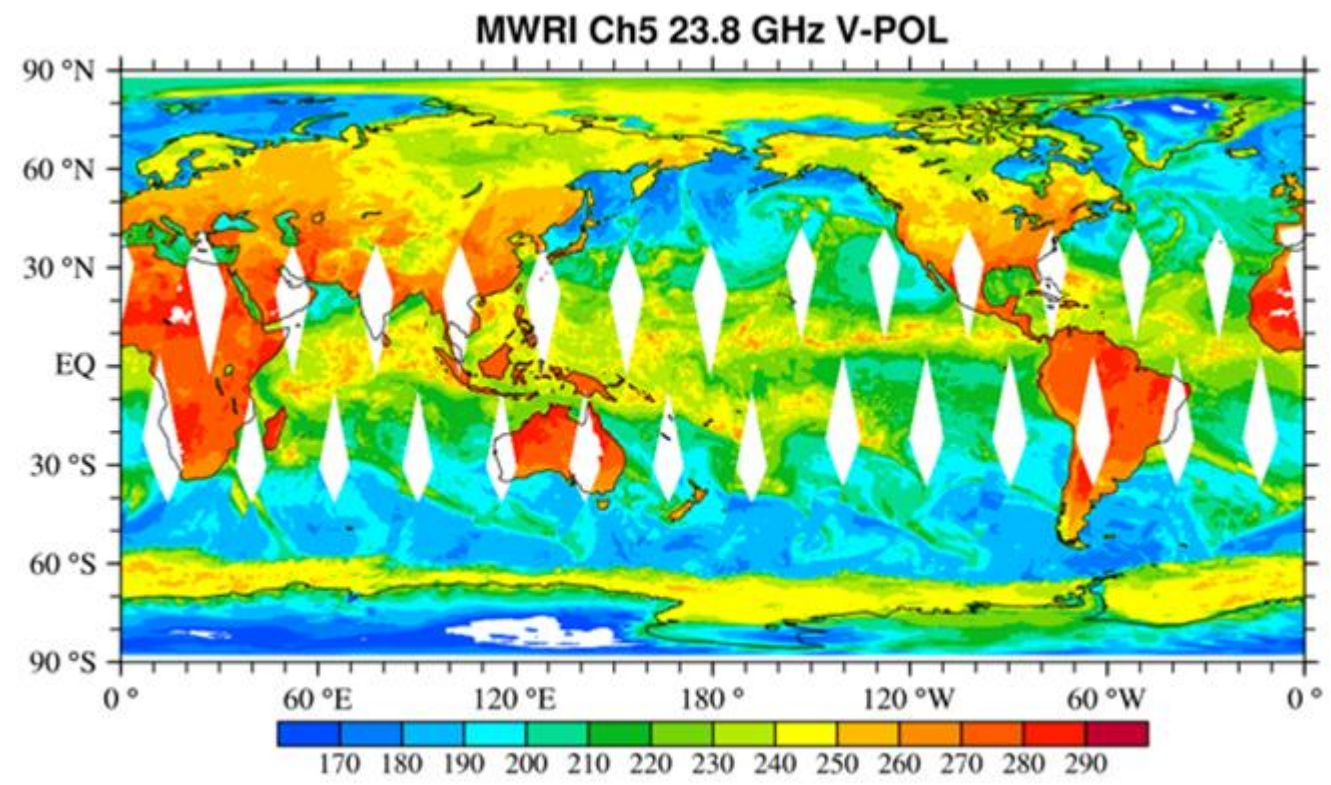

Figure 1. The coverage of channel 5's scanning in one day.

MWRI weighting functions calculated from the U.S. Standard Atmosphere model with CRTM are shown in Figure 2. Similar to the AMSR2 channels, it can be seen that all channels' peaks were located at surface levels, which meant a clear sky atmosphere was transparent for the MWRI channels.

\subsection{Quality Control}

A variety of quality-control produces were applied to the MWRI radiance data, including: (1) a surface-type check, which rejected pixels with mixed surface types; (2) all pixels over land were removed because of a worse land-emissivity calculation; (3) for $10.6 \mathrm{GHz}$ channels, data were not used for a sun-glint angle of less than 25.0 degrees; (4) a departure check, which removed pixels with innovation that exceeded 3 times the observation error standard deviation; (5) a cloud check that rejected pixels for which the CLWP (Cloud Liquid Water Path) from background was larger than thresholds. 


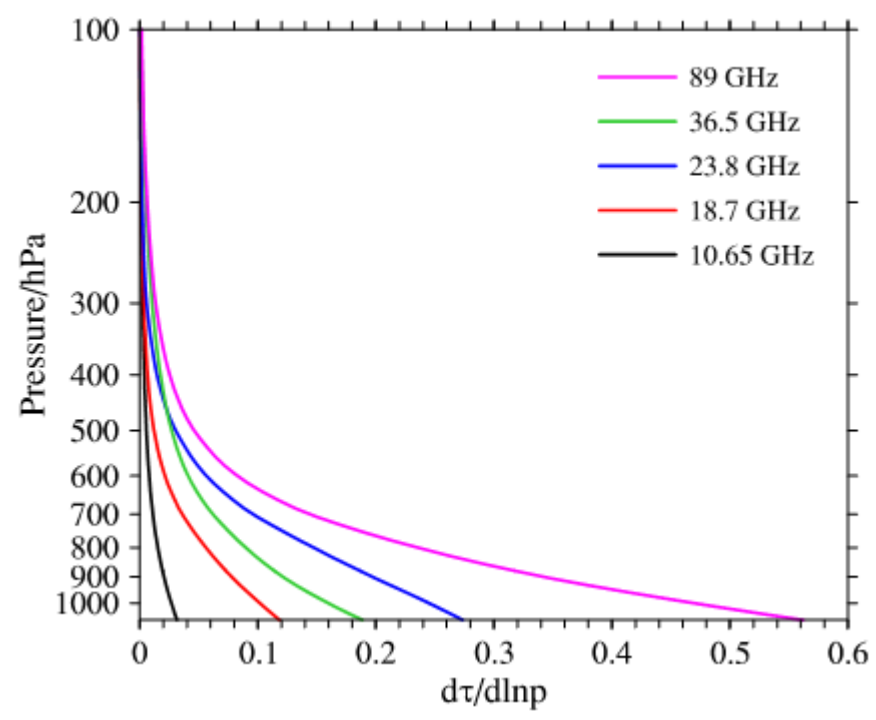

Figure 2. The weighting function of the MWRI.

\section{Experimental Setup}

Typhoon Son-Tinh (2012) was selected to evaluate the impact of MWRI radiance assimilation under clear-sky conditions. As shown in Figure 3, Son-Tinh appeared as a low-pressure system southeast of Yap and was identified as a tropical storm later on 23 October, and named Son-Tinh. It moved toward the southwest at $25 \mathrm{~km} / \mathrm{h}$, and first landed at Surigao del Norte in the Philippines. Son-Tinh grew and passed over the south of the Philippines, then it moved into the South China Sea and intensified to typhoon strength at 1800 UTC on 26 October. It was upgraded to a Category 3 typhoon with a maximum surface wind speed (MSWS) of 85 knots and a minimum sea level pressure (MSLP) of $945 \mathrm{hPa}$ at $1200 \mathrm{UTC}$ on 27 October, prior to its second landfall at Teri County in Vietnam on 28 October. Son-Tinh quickly weakened to tropical-storm status after landing. Initially, it moved northwest, but turned northward after its second landfall. Son-Tinh resulted in a total of 30 deaths in the Philippines, China, and Vietnam, and forced about 150,000 people to relocate.

Two cycling assimilation experiments and one forecast experiment without data assimilation were constructed to verify the impact of assimilating MWRI radiance data on the forecast and analysis of Typhoon Son-Tinh with the WRF model and WRFDA system. For all experiments, the assimilations were performed every $6 \mathrm{~h}$ (at 0000, 0600,1200 and 1800 UTC) from 0600 UTC on 22 October to 1200 UTC on 28 October 2012. The first analysis's background of assimilation experiments was the $6 \mathrm{~h}$ forecast at $0000 \mathrm{UTC}$ on 22 October. The National Center of Environmental Prediction (NCEP) Global Forecast System (GFS) forecasts at $0.25^{\circ}$ with a time resolution of $6 \mathrm{~h}$ provided the lateral boundary conditions of every forecast and the initial conditions used for low-boundary updating. In each cycle, the background was the $6 \mathrm{~h}$ WRF forecast from the previous cycle's analysis, except for the first background at 0600 UTC on 22 October, which was from the GFS analysis. In order to estimate the assimilation effect on a long forecast, a $48 \mathrm{~h}$ forecast was initialized from each 0000 and 1200 UTC analysis of assimilation experiments. All $6 \mathrm{~h}$ and $48 \mathrm{~h}$ forecasts were generated with version 3.8 of the Advanced Research WRF Model (WRF-ARW) [24]. The configuration of each experiment was characterized by horizontal grid spacing of $15 \mathrm{~km}$ and 57 vertical levels. The physics parameterizations used in this study are shown in Table 2: 


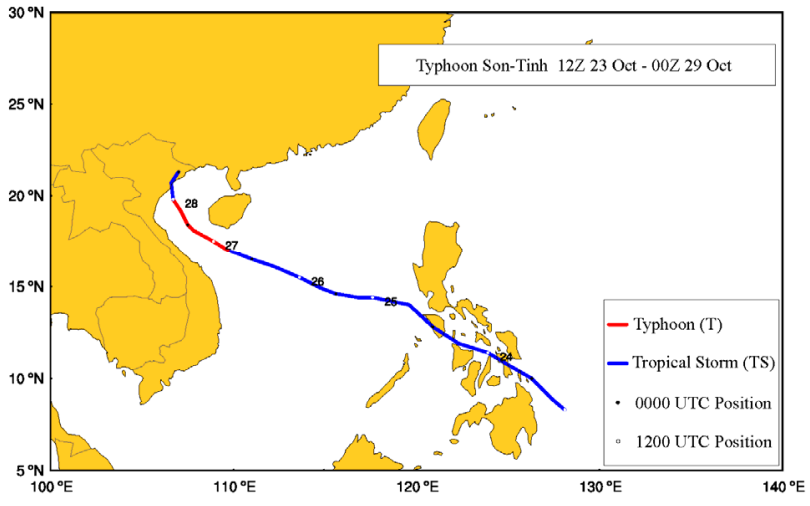

(a)

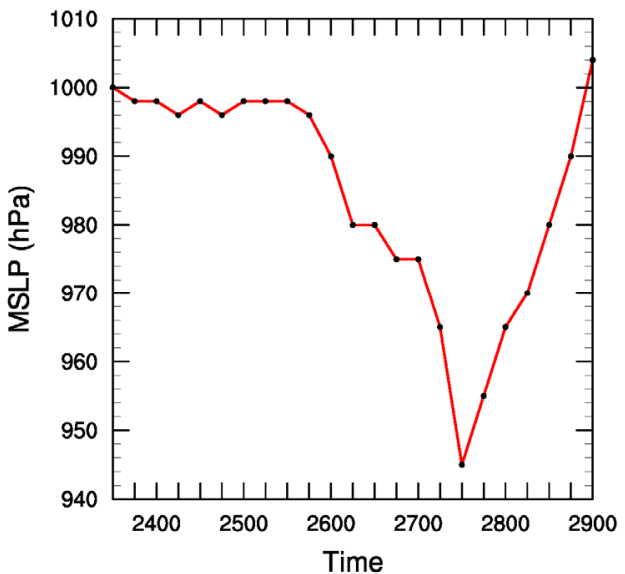

(b)

Figure 3. The (a) best track and (b) minimum sea level pressure (MSLP) of Typhoon Son-Tinh.

Table 2. The configuration of the physics parameterizations.

\begin{tabular}{cc}
\hline Physics Parameterization & Configuration \\
\hline Microphysics scheme & WRF single-moment 6-class scheme (WSM6) [25] \\
\hline Shortwave- and longwave-radiation schemes & $\begin{array}{c}\text { Rapid Radiative Transfer Model for GCMs } \\
\text { (RRTMG) [26,27] }\end{array}$ \\
\hline Boundary-layer scheme & Yonsei University scheme (YSU) [28] \\
\hline Surface-layer scheme & Monin-Obukhoy scheme [29] \\
\hline Land-surface model & Unified NOAH land-surface model [30] \\
\hline Cumulus-parameterization scheme & Tiedtke scheme [31,32]
\end{tabular}

Since the aim was to estimate the impact of assimilating MWRI radiance with 3DVAR on the analysis and forecast of Typhoon Son-Tinh, one forecast experiment without data assimilation and two primary assimilation experiments were designed, named as CTL, CON, and AMWRI:

i. The control experiment (CTL), which only made a single forecast from the start time to the end with no data assimilation.

ii. The conventional assimilation experiment $(\mathrm{CON})$, which assimilated conventional observations from radiosondes, aircraft, satellite-derived winds, land and oceanic surface stations, and GPS refractivity observations. These observations provided the information on temperature, wind, humidity, surface pressure, and so on. All types of data were assimilated at the analysis time with a $2 \mathrm{~h}$ assimilation time window, which meant the observations within $\pm 1 \mathrm{~h}$ of the analysis times were assimilated at the analysis time together. More than 10,000 conventional observations were assimilated at a time.

iii. The MWRI assimilation experiment (AMWRI), which also assimilated conventional observation like CON, and additionally assimilated clear-sky MWRI radiance data. The assimilation time window of the satellite was $6 \mathrm{~h}$. The thinning mesh of MWRI radiance data was an $80 \mathrm{~km}$ grid to avoid potential correlations between adjacent observations [33]. Because of the advantages of satellites, AMWRI could gain more accurate data over the typhoon region.

The background error covariance statistics of each assimilation experiment were created using the NMC (National Meteorological Center) method [34]. Figure 4 shows the distribution of conventional data assimilated in two experiments at 1200 UTC on 26 October. Among all observations, the satellite-derived winds (named as "satob") shown as cyan dots took up $86 \%$, and most of them were over the Pacifica Ocean. 


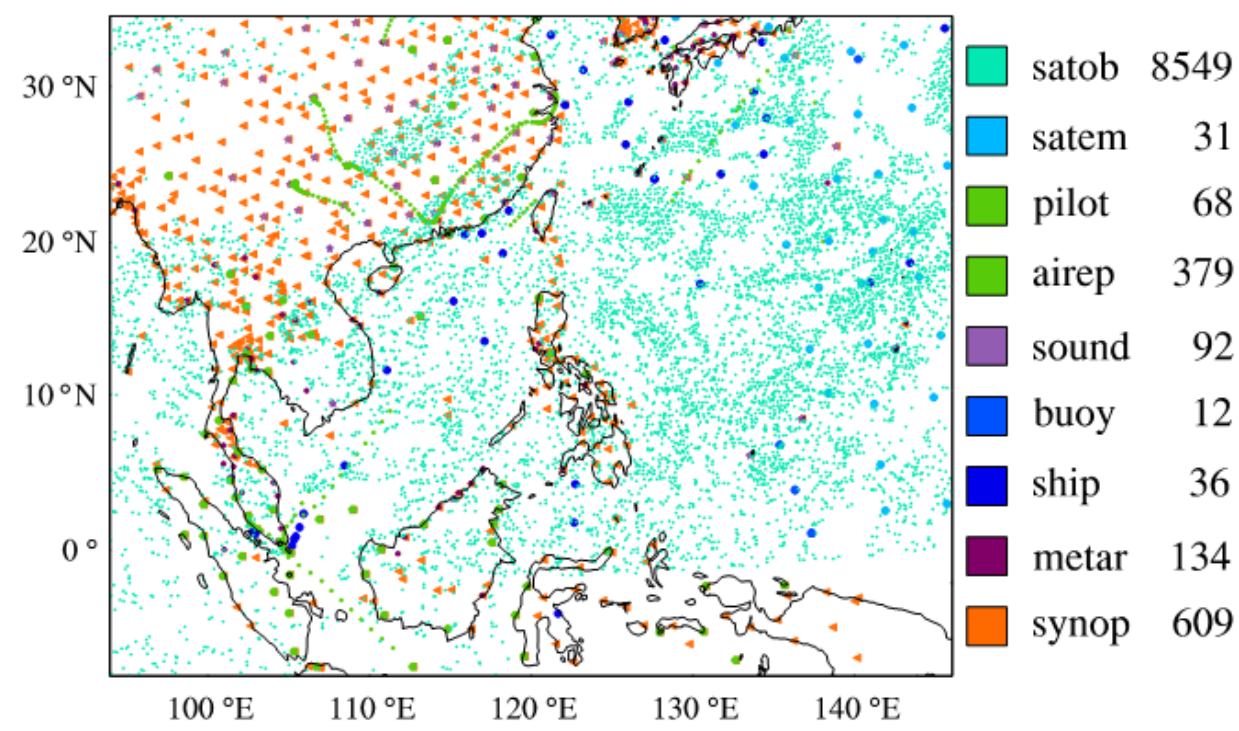

Figure 4. The distribution of observations used in the CON experiment at 1200 UTC on 26 October 2012. The numbers of each observation are marked on the right.

\section{Results}

\subsection{Impact on the Analysis of Son-Tinh}

At 1800 UTC on 26 October, Typhoon Son-Tinh moved into the South China Sea and strengthened to a typhoon, and we chose the analysis of the storm as the example to estimate the impact of MWRI assimilation. With $6 \mathrm{~h}$ assimilation time window, there were three tracks of MWRI data in the experiment domain area, with one track over SonTinh. Figure 5 shows the spatial distribution of the observed (Figure 5a) and assimilated (Figure $5 \mathrm{~b}$ ) brightness temperature with an $80 \mathrm{~km}$ thinning mesh at 1800 UTC on 26 October. We noted that there are many outlier observations related to the ascending/descending orbit along the coast in Figure 5a. They were the result of inaccurate geolocation. Nevertheless, they were rejected before entering the data assimilation by quality control (Figure $5 b$ ) based on larger bias. Meanwhile, because of the clear-sky simulation, many observations over Typhoon Son-Tinh were removed by the cloud check.

Figure 6 illustrates a comparison of the CTL forecast (Figure 6b), CON analysis (Figure 6c), and the AMWRI analysis (Figure 6d) by all-sky CRTM simulation of channel 5. From the observation (Figure 6a), Typhoon Son-Tinh lay to the south of Hainan at 1800 UTC on 26 October with a larger brightness temperature. Son-Tinh had a clear spiraling cloud band that stretched from Hainan to the coast of Malaysia. It was also seen in the analyzed brightness temperature of the $\mathrm{CON}$ and the AMWRI experiments, but was more irregular in CTL. Moreover, the CTL showed the weakest brightness temperature over the whole region of Son-Tinh, while the CON also showed lower brightness temperature to the south of Vietnam with a narrower cloud band, but a higher brightness temperature to the north of New Guinea. In contrast, the AMWRI experiment's gained analyzed brightness temperature was closer to the observed values near the center of Son-Tinh and the cloud band, which resulted from the assimilation of the MWRI data. The correlation between the AMWRI analysis and MWRI observation was 0.94 , which was higher than 0.88 for CON and 0.79 for CTL. 


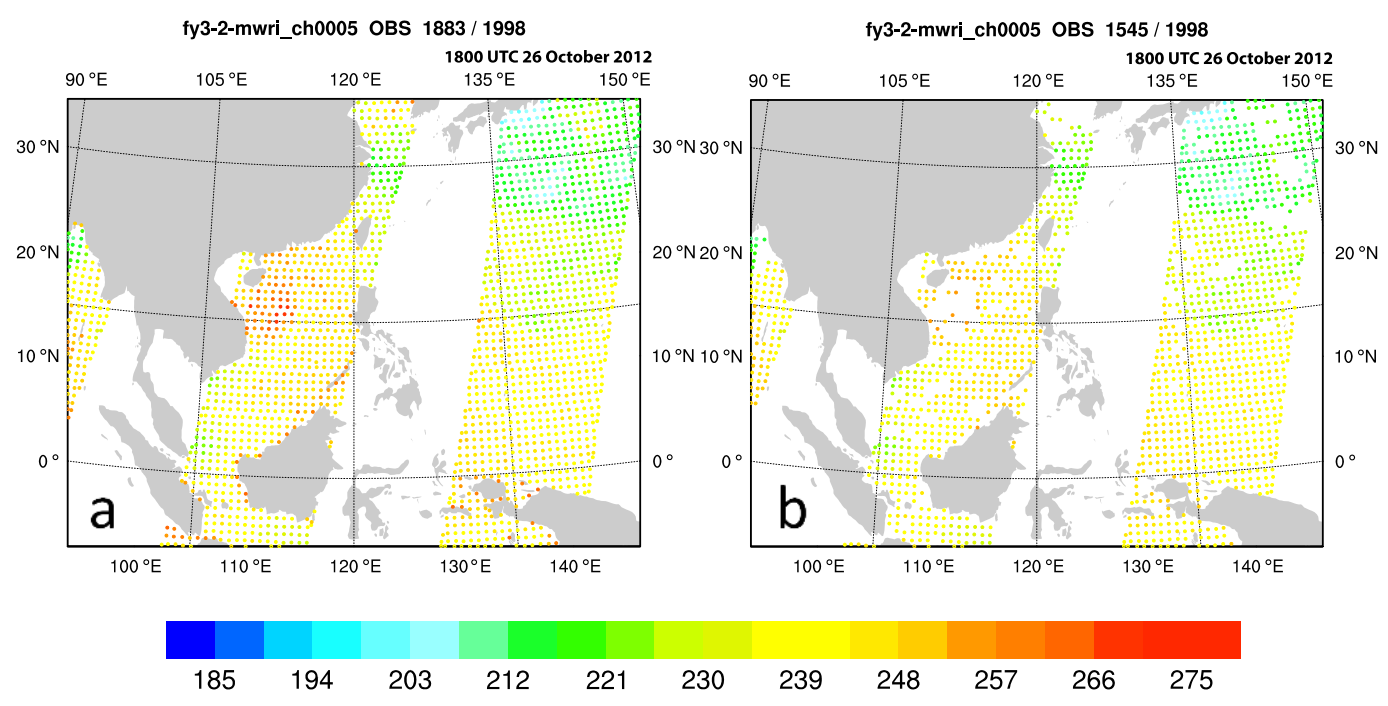

Figure 5. The distribution of channel 5 observations: (a) before quality control; (b) after quality control.
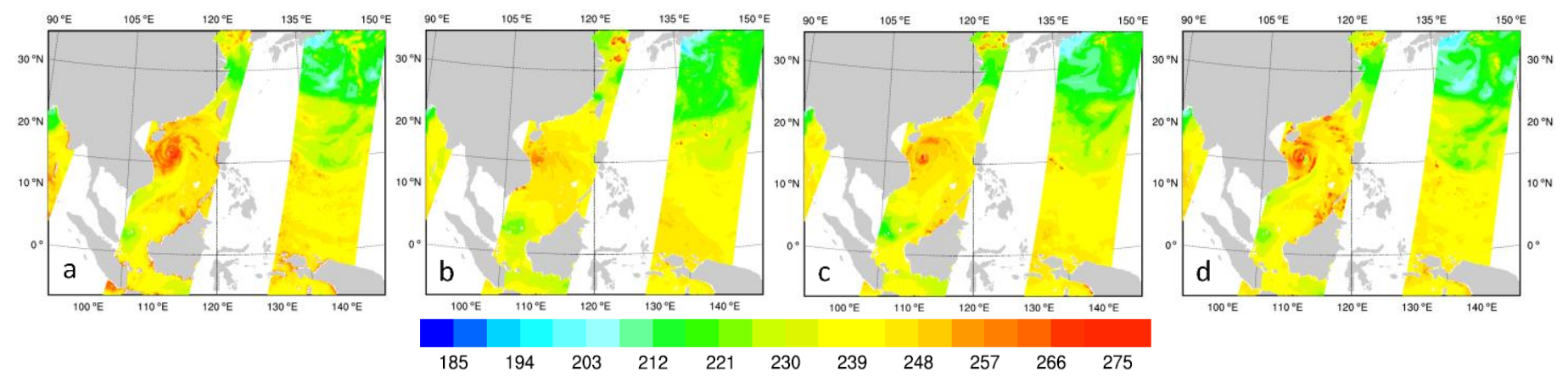

Figure 6. The analyzed brightness temperatures (K) of MWRI $23.8 \mathrm{GHz}-\mathrm{V}$ channel 5 from (a) observation, (b) CTRL, (c) CON, and (d) AMWRI experiments at 1800 UTC on 26 October.

The ECMWF analysis with $16 \mathrm{~km}$ resolution, which had a similar resolution to the experiment, was chosen to verify the WRFDA analysis fields. The fields of surface wind, sea level pressure (SLP), temperature anomaly, and horizontal wind speed from the ECMWF analysis and from the forecast of the CTL and the analyses of the CON and AMWRI at 1800 UTC on 26 October are shown in Figure 7, at the surface level and in vertical cross-sections through the individual vortex centers of each experiment. Compared with ECMWF analysis (Figure 7a), the CTL (Figure 7b) gained lower SLP and smaller surface wind. Furthermore, it is clear that Son-Tinh's center in the CTL was located to the southwest of the ECMWRF analysis. The CON (Figure 7c) obtained a higher SLP and smaller surface wind, while the AMWRI (Figure 7d) experiment analysis showed a more similar but stronger pattern of Son-Tinh. However, according to the best track data from the Japan Meteorological Agency (JMA), the MSLP of Son-Tinh at 1800 UTC on 26 October was $975 \mathrm{hPa}$, which was stronger than the ECMWF analysis, but similar to that of the AMWRI. Therefore, the analysis of the AMWRI was closer to the best track data than the ECMWF. 

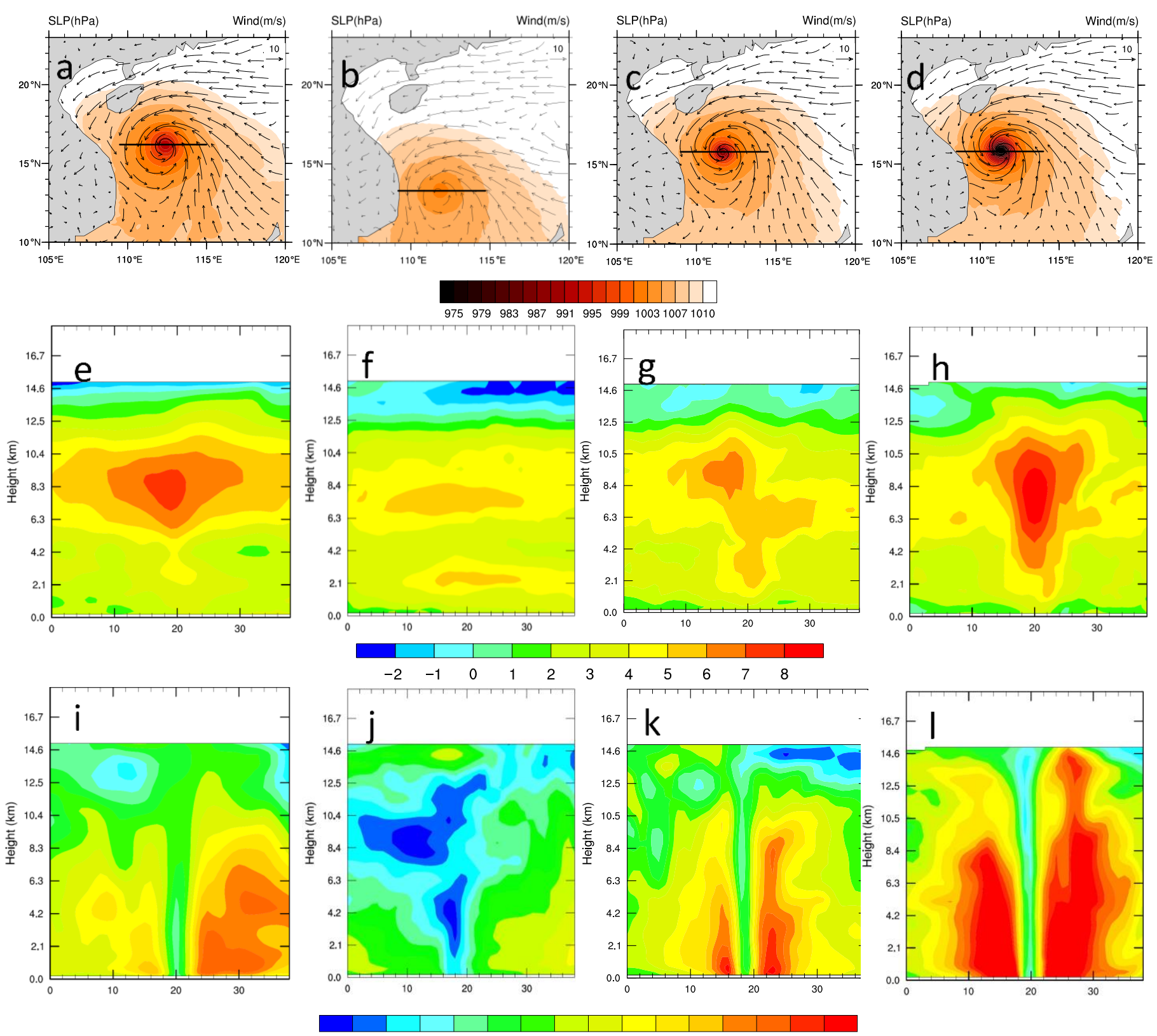

$\begin{array}{lllllllllllllll}2 & 4 & 6 & 8 & 10 & 12 & 14 & 16 & 18 & 20 & 22 & 24 & 26 & 28 & 30\end{array}$

Figure 7. (a-d) The surface wind vectors and sea level pressure (color-shaded) from the analyses of the ECMWF, CTRL, CON, and AMWRI, respectively; (e-h) the west-east cross-sections of temperature anomalies for the ECMWF, CTRL, CON, and AMWRI, respectively; and (i-1) the horizontal wind speed through the vortex center for the ECMWF, CTRL, CON, and AMWRI, respectively, at 1800 UTC on 26 October. The $x$-axis of (e-1) is the grid number along the black line in (a).

The vertical cross-sections of temperature anomaly are shown in Figure $7 \mathrm{e}-\mathrm{h}$. It is clear that an obvious warm heat appears around $8.3 \mathrm{~km}$ in Figure $7 \mathrm{e}$. At the cyclone center, the warm belt ranges from $2.1 \mathrm{~km}$ to $12.5 \mathrm{~km}$. In the CTL (Figure 7f) experiment, there was no significant warm core. In the CON experiment (Figure $7 \mathrm{~g}$ ), there was an irregular warm core at $9 \mathrm{~km}$, and the strength of warm belt was lower than in the ECMWF analysis. By contrast, for the AMWRI (Figure 7h), there was a distinct warm core that was larger than in the CTL, CON, and ECMWF, extending from $1.1 \mathrm{~km}$ to $12.5 \mathrm{~km}$. The horizontal winds pattern of Son-Tinh in Figure 7i,l show that Son-Tinh was an approximately symmetrical typhoon. Compared with the ECMWF, except for the CTL, the CON and AMWRI obtained much stronger horizontal wind. At the typhoon center, which corresponds to a minimum horizontal wind center, the CON was larger than the AMWRI and ECMWF. According to 
the JMA best-track data, the maximum wind speed at this moment was 60 knots, about $31 \mathrm{~m} / \mathrm{s}$. Therefore, the result from the AMWRI was closer to the realistic strength.

\subsection{Impact on the Forecast of Son-Tinh}

Because the CTL only had one lead time and one forecast, it did not match the forecasts from assimilation experiments. In order to highlight the impact of the MWRI assimilation, the results of the CTL are not discussed in this section. For the CON and AMWRI, a $48 \mathrm{~h}$ WRF forecast was initialized from each 0000 and 1200 UTC analysis. The aggregated rootmean-square error (RMSE) profiles of wind vector, temperature, geopotential height, and moisture forecasts verified against the ECMWF analysis at $24 \mathrm{~h}$ and $48 \mathrm{~h}$ for all 12 two-day forecasts are displayed in Figure 8. For the $24 \mathrm{~h}$ forecasts, the significant improvements of MWRI assimilation on wind field and geopotential height field were at $925 \mathrm{hPa}$ and below and the middle-high levels $(500-50 \mathrm{hPa})$. The improvement in temperature field was located at the low-middle levels $(1000-300 \mathrm{hPa})$. The pronounced positive impact of MWRI assimilation on specific humidity could be found from $925 \mathrm{hPa}$ to $200 \mathrm{hPa}$ (Figure 8a). For the $48 \mathrm{~h}$ forecasts, the gap between two RMSE profiles for the CON and AMWRI was similar to the $24 \mathrm{~h}$ forecasts. The AMWRI still obtained some definite improvements in geopotential height and specific humidity fields (Figure $8 \mathrm{~b}$ ). This indicates the positive impact of the MWRI assimilation on forecasts, and that it is useful for long-term forecasts.
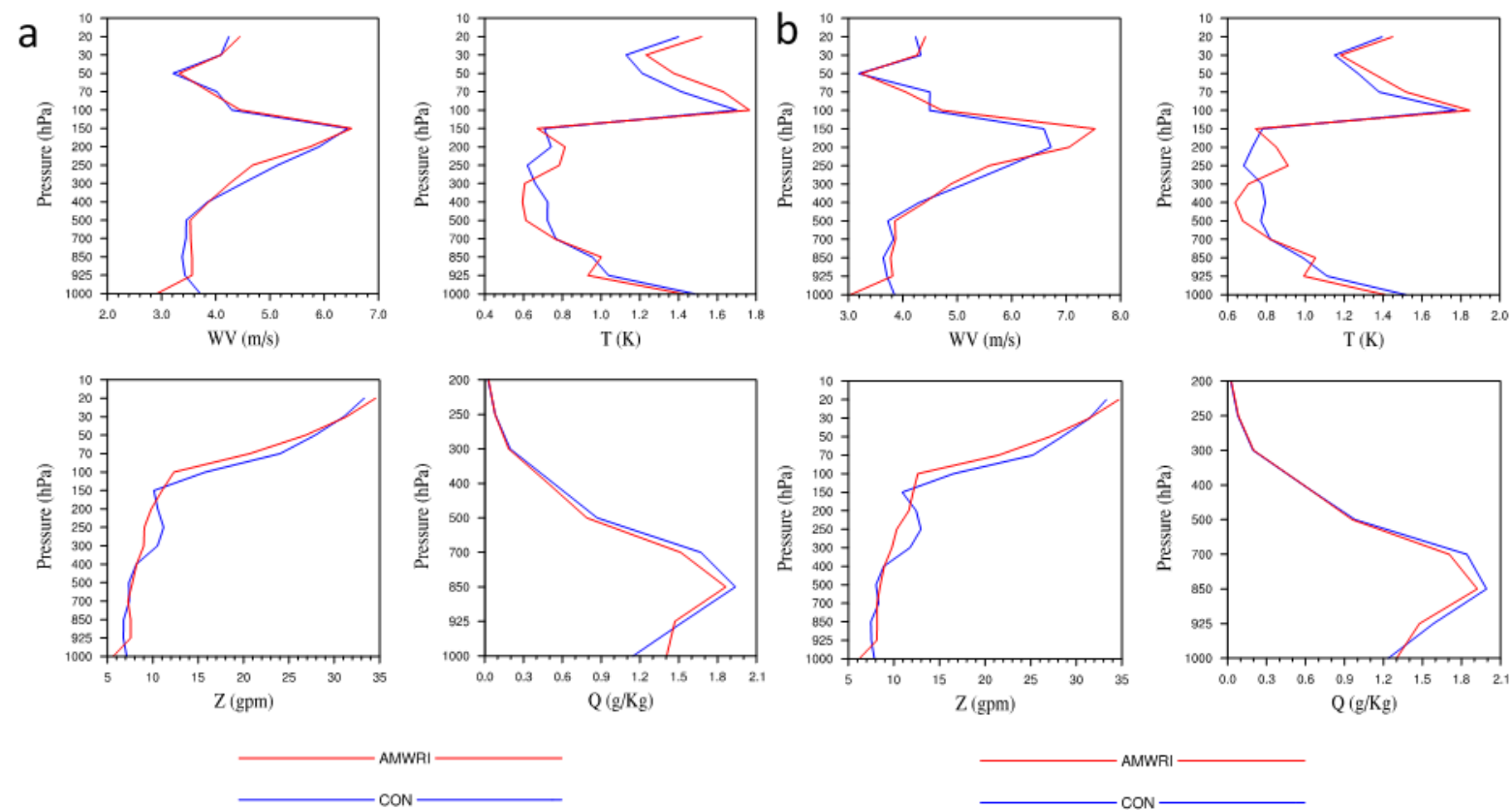

Figure 8. The aggregated root-mean-square errors of the (a) $24 \mathrm{~h}$ and (b) $48 \mathrm{~h}$ forecasts for vector wind, temperature, geopotential height, and specific humidity against the ECMWF analyses. The error statistics were obtained from $12 \mathrm{~h}$ and $48 \mathrm{~h}$ forecasts.

The impact of assimilating MWRI radiance data on Son-Tinh's track and intensity forecast were evaluated with the JMA best-track data. Figure 9 shows the mean aggregated errors of the track, central sea level pressure (CSLP), and max wind speed (MWS) of $12 \mathrm{~h}$ and $48 \mathrm{~h}$ forecasts from the CON and AMWRI. As shown in Figure 9a, the forecast error of the track increased with time in both the CON and AMWRI. Nevertheless, MWRI assimilation reduced track error before $48 \mathrm{~h}$ forecast with the greatest reduction (45\%). With the MWRI assimilation, consistent improvements for all lead times were obtained on the CSLP (Figure 9b). The improvement of the CSLP was at the assimilation time, with $50 \%$ error reduction, and became more obvious against the forecast time. For the MWS (Figure $9 b$ ), the result of the AMWRI decreased with forecast time and finally became stable at about $8 \mathrm{~m} / \mathrm{s}$, while the CON increased and stabilized at $12 \mathrm{~m} / \mathrm{s}$. There was a $45 \%$ 
improvement in the AMWRI. From Figure 9c, it is clear that the AMWRI overestimated the intensity of Son-Tinh, while the CON underestimated Son-Tinh's intensity for all lead times.
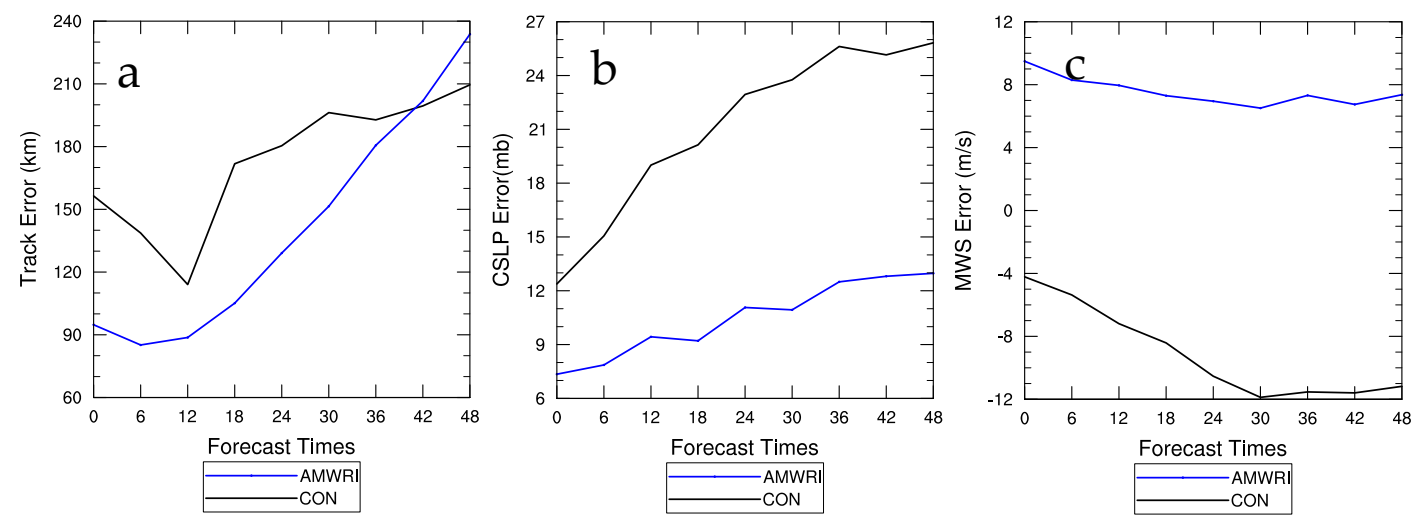

Figure 9. (a) Aggregated absolute track errors, (b) mean central sea level pressure errors, and (c) maximum wind speed as a function of forecast range from two experiments. The error statistics were obtained from $1248 \mathrm{~h}$ forecasts.

\section{Discussion and Conclusions}

The microwave imager can measure the upwelling thermal emissions from the surface, and is sensitive to soil moisture, soil temperature, snow cover, and other surface parameters. Therefore, microwave imager data are frequently used to retrieve these surface parameters. Meanwhile, some retrieval data from microwave imagers are assimilated in several operational centers. However, many previous studies strongly suggested that directly assimilating microwave radiance data is better than retrieval data [35].

Consequently, in order to estimate the benefit of directly assimilating microwave imager radiance data, the module of the MWRI in HDF (Hierarchical Data Format) format was first configured in WRFDA with CRTM. This study was an attempt to directly assimilate clear-sky FY-3B-MWRI radiance data using WRFDA with the 3DVAR scheme, and to evaluate its impact on the analyses and forecasts of Typhoon Son-Tinh (2012). Two forecast-analysis cycling experiments and one single-forecast experiment without data assimilation were implemented using WRF and WRFDA-3DVAR with GFS data as the initial condition and boundary condition.

With the quality control schemes, more outlier observations were rejected, especially the observations close to coastlines with larger bias. Compared to a benchmark experiment (CTL), conventional assimilation (CON) and MWRI radiance assimilation (AMWRI) improved the typhoon-structure analysis. With the assimilation of MWRI radiance data, AMWRI analyses obtained much more accurate cloud distribution and higher correlation with satellite observation than the CON and CTL. All experiments could successfully depict the patten of Son-Tinh; however, MWRI assimilation brought stronger CSLP than the CTL, CON, and ECMWRF analyses, and was in closest agreement with the best-track data. Better warm core and maximum wind speed analyses were also produced by assimilating MWRI data. Moreover, the assimilation of MWRI data verified with ECMWF analyses data obtained definite improvements in geopotential height and specific humidity fields from the $24 \mathrm{~h}$ forecast to the $48 \mathrm{~h}$ forecast. Furthermore, significant error reduction on track, CSLP, and MWS were gained from analysis of the $48 \mathrm{~h}$ forecast. For this case, a positive impact of assimilating MWRI was achieved.

This is the first case study to verify the advantage of FY-3B-MWRI assimilation with WRFDA. To further consolidate the conclusions drawn here, more experiments for different cases are needed. In addition, much further improvement could be made for MWRI assimilation in future studies. For example, nesting has been proved to be a key role for simulation with WRF [36], and thus can be used to improve the simulation of tropical cyclones. Moreover, all-sky assimilation of microwave imager data could assimilate more 
observation under clouds and precipitation to provide more accurate convective structure information [5].

Compared with other studies on MWRI retrieval data, this study focused on the impact of directly assimilating MWRI radiance data, which avoided the extra error in retrieval calculation. In addition, the self-developed FY-3B-MWRI assimilation module was interfaced with the WRFDA system, which can provide a research platform for further experiments with MWRI data.

Author Contributions: C.Y. conceived and designed the overall project and wrote most sections of the manuscript; L.Z. performed part of the analysis; J.M. supplied suggestions and comments for the manuscript. All authors have read and agreed to the published version of the manuscript.

Funding: This research was funded by the National Key Research and Development Program of China (Grant No. 2017YFC1502102), the National Natural Science Foundation of China (Grant No. 41805071), the Startup Foundation for Introducing Talent of Nanjing University of Information Science and Technology (Grant No. 2017r058).

Institutional Review Board Statement: Not applicable.

Informed Consent Statement: Not applicable.

Data Availability Statement: Not applicable.

Conflicts of Interest: The authors declare no conflict of interest.

\section{References}

1. Kazumori, M.; Liu, Q.; Treadon, R.; Derber, J.C. Impact study of AMSR-E radiances in the NCEP global data assimilation system. Mon. Weather Rev. 2008, 136, 541-559. [CrossRef]

2. Bauer, P.; Auligne', T.; Bell, W.; Geer, A.J.; Guidard, V.; Heilliette, S.; Kazumori, M.; Kim, M.; Liu, E.H.; McNally, A.P.; et al. Satellite cloud and precipitation assimilation at operational NWP centres. Q. J. R. Meteorol. Soc. 2011, 137, 1934-1951. [CrossRef]

3. Geer, A.J.; Bauer, P. Enhanced Use of All-Sky Microwave Observations Sensitive to Water Vapor, Cloud and Precipitation; Technical Memorandum; ECMWF: Reading, UK, 2010; Volume 620, p. 41.

4. Kazumori, M. Satellite radiance assimilation in the JMA operational mesoscale 4DVAR system. Mon. Weather Rev. 2014, 142, 1361-1381. [CrossRef]

5. Yang, C.; Liu, Z.; Bresch, J.; Rizvi, S.R.H.; Hang, X.; Min, J. AMSR2 all-sky radiance assimilation and its impact on the analysis and forecast of Hurricane Sandy with a limited-area data assimilation system. Tellus A 2016, 68, 30917. [CrossRef]

6. Yang, C.; Liu, Z.; Gao, F.; Childs, P.P.; Min, J. Impact of assimilating GOES imager clear-sky radiance with a rapid refresh assimilation system for convection-permitting forecast over Mexico. J. Geo. Res. 2017, 122, 5472-5490. [CrossRef]

7. Zhang, F.; Minamide, M.; Nystrom, R.G.; Chen, X.; Lin, S.; Harris, L.M. Improving Harvey Forecasts with Next-Generation Weather Satellites: Advanced Hurricane Analysis and Prediction with Assimilation of GOES-R All-Sky Radiances. Bull. Am. Meteorol. Soc. 2019, 100, 1217-1222. [CrossRef]

8. Zhu, Y.; Gayno, G.; Purser, R.J.; Su, X.; Yang, R. Expansion of the All-Sky Radiance Assimilation to ATMS at NCEP. Mon. Weather Rev. 2019, 147, 2603-2620. [CrossRef]

9. Yang, H.; Lv, L.; Xu, H.; He, J.; Wu, S. Evaluation of FY3B-MWRI instrument on-orbit calibration accuracy. In Proceedings of the IEEE International Geoscience and Remote Sensing Symposium, IGARSS 2011, Vancouver, BC, Canada, 24-29 July 2011; IEEE: Piscataway, NJ, USA, 2011.

10. Xu, D.; Liu, Z.; Huang, X.; Min, J.; Wang, H. Impact of assimilation IASI radiance observations on forecasts of two tropical cyclones. Meteorol. Atmos. Phys. 2013, 122, 1-18. [CrossRef]

11. Xu, D.; Min, J.; Shen, F.; Ban, J.; Chen, P. Assimilation of MWHS radiance data from the FY-3B satellite with the WRF Hybrid3DVAR system for the forecasting of binary typhoons. J. Adv. Model. Earth Syst. 2016, 8, 1014-1102. [CrossRef]

12. Bell, W.; Candy, B.; Atkinson, N.; Hilton, F.; Baker, N.; Bormann, N.; Kelly, G.; Kazumori, M.; Campbell, W.; Swadley, S. The assimilation of SSMIS radiances in numerical weather prediction models. IEEE Trans. Geosci. Remote Sens. 2008, 46, 884-900. [CrossRef]

13. Kunkee, D.B.; Poe, G.A.; Boucher, D.J.; Swadley, S.D.; Hong, Y.; Wessel, J.E.; Uliana, E.A. Design and evaluation of the first Special Sensor Microwave Imager/Sounder. IEEE Trans. Geosci. Remote Sens. 2008, 46, 863-883. [CrossRef]

14. Kawanishi, T.; Sezai, T.; Ito, Y.; Imaoka, K.; Takeshima, T.; Ishido, Y.; Shibata, A.; Miura, M.; Inahata, H.; Spencer, R. The Advanced Microwave Scanning Radiometer for the Earth Observing System (AMSR-E), NASDA's contribution to the EOS for global energy and water cycle studies. IEEE Trans. Geosci. Remote Sens. 2003, 41, 184-194. [CrossRef]

15. Kazumori, M.; Egawa, T. Assimilation of GCOM-W/AMSR2 radiance data in the JMA NWP systems. In WGNE Blue Book: Research Activities in Atmospheric and Ocean Modeling; WMO/Working Group on Numerical Experimentation: Geneva, Switzerland, 2014; Volume 1, pp. 7-8. 
16. Parinussa, R.M.; Wang, G.; Holmes, T.R.H.; Liu, Y.Y.; Dolman, A.J.; De Jeu, R.A.M.; Jiang, T.; Zhang, P.; Shi, J. Global surface soil moisture from the Microwave Radiation Imager onboard the Fengyun-3B satellite. Int. J. Remote Sens. 2014, 35, 7007-7029. [CrossRef]

17. Cui, Y.; Long, D.; Hong, Y.; Zeng, C.; Zhou, J.; Han, Z.; Liu, R.; Wan, W. Validation and reconstruction of FY-3B/MWRI soil moisture using an artificial neural network based on reconstructed MODIS optical products over the Tibetan Plateau. J. Hydrol. 2016, 543, 242-254. [CrossRef]

18. Yang, J.; Jiang, L.; Shi, J.; Wu, S.; Sun, R.; Yang, H. Monitoring snow cover using Chinese meteorological satellite data over China. Remote Sens. Environ. 2014, 143, 192-203. [CrossRef]

19. Wu, L.; Li, X.; Zhao, K.; Zheng, X.M.; Dai, L.Y. Validation and Analysis of Snow Depth Inversion Algorithm in Northeast Typical Forest Based on the FY3B-MWRI Data. J. Geo-Inf. Sci. 2014, 16, 320-327.

20. Xu, B.; Xie, P.; Xu, M.; Jiang, L.; Shi, C.; You, R. A Validation of Passive Microwave Rain-Rate Retrievals from the Chinese FengYun-3B Satellite. J. Hydrometeorol. 2015, 16, 1886-1905. [CrossRef]

21. Barker, D.M.; Huang, X.; Liu, Z.; Auligné, T.; Zhang, X.; Rugg, S.; Ajjajj, R.; Bourgeois, A.; Bray, J.; Chen, Y.; et al. The weather research and forecasting (WRF) model's community variational/ensemble data assimilation system: WRFDA. Bull. Am. Meteorol. Soc. 2012, 93, 831-843. [CrossRef]

22. Weng, F. Advances in radiative transfer modeling in support of satellite data assimilation. J. Atmos. Sci. 2007, 64, 3799-3807. [CrossRef]

23. Han, Y. JCSDA Community radiative Transfer Model (CRTM)_Version 1; NOAA Technical Report; NESDIS: Washington, DC, USA, 2006; Volume 122, p. 33.

24. Skamarock, W.C.; Klemp, J.B.; Dudhia, J.; Gill, D.O.; Barker, D.M.; Wang, W.; Powers, J.G. A Description of the Advanced Research WRF Version 3; NCAR Technical Note NCAR/TN-475_STR; CiteSeerX: State College, PA, USA, 2008; p. 133.

25. Hong, S.; Lim, J.J. The WRF Single-Moment 6-Class Microphysics Scheme (WSM6). J. Korean Meteor. Soc. 2006, 42, 129-151.

26. Mlawer, E.J.; Taubman, S.J.; Brown, P.D.; Iacono, M.J.; Clough, S.A. Radiative transfer for inhomogeneous atmosphere: RRTM, a validated correlated-k model for the long-wave. J. Geophys. Res. 1997, 102, 16663-16682. [CrossRef]

27. Iacono, M.J.; Delamere, J.S.; Mlawer, E.J.; Shephared, M.W.; Clough, S.A.; Collins, W.D. Radiative forcing by longlived greenhouse gases: Calculations with the AER radiative transfer models. J. Geophys. Res. 2008, 113, D13103. [CrossRef]

28. Hong, S.; Noh, Y.; Dudhia, J. A new vertical diffusion package with an explicit treatment of entrainment processes. Mon. Weather Rev. 2006, 134, 2318-2341. [CrossRef]

29. Monin, A.S.; Obukhov, A.M. Basic laws of turbulent mixing in the surface layer of the atmosphere. Contrib. Geophys. Inst. Slovak Acad. Sci. 1954, 24, 163-187.

30. Chen, F.; Dudhia, J. Coupling an advanced land-surface/hydrology model with the Penn State/NCAR MM5 modeling system Part I: Model description and implementation. Mon. Weather Rev. 2001, 129, 569-585. [CrossRef]

31. Tiedtke, M. A comprehensive mass flux scheme for cumulus parameterization in large-scale models. Mon. Weather Rev. 1989, 117, 1779-1800. [CrossRef]

32. Zhang, C.; Wang, Y.; Hamiltion, K. Improved representation of boundary layer clouds over the southeast Pacific in ARW-WRF using a modified Tiedtke cumulus parameterization scheme. Mon. Weather Rev. 2011, 139, 3489-3513. [CrossRef]

33. Liu, Z.; Rabier, F. The interaction between model resolution, observation resolution and observation density in data assimilation: A one-dimensional study. Q. J. R. Meteorol. Soc. 2002, 128, 1367-1386. [CrossRef]

34. Parrish, D.F.; Derber, J.C. The National Meteorological Center's spectral statistical interpolation analysis system. Mon. Weather Rev. 1992, 120, 1747-1763. [CrossRef]

35. Moreau, E.; Lopez, P.; Bauer, P.; Tompkins, A.M.; Janiskova, M.; Chevallier, F. Variational retrieval of temperature and humidity profiles using rain rates versus microwave brightness temperatures. Q. J. R. Meteorol. Soc. 2004, 130, 617-628. [CrossRef]

36. Caccamo, M.T.; Castorina, G.; Colombo, F.; Insinga, V.; Maiorana, E.; Mazagu, S. Weather forecast performances for complex orographic areas: Impact of different grid resolutions and of geographic data on heavy rainfall event simulations in Sicily. Atmos. Res. 2017, 198, 22-33. [CrossRef] 